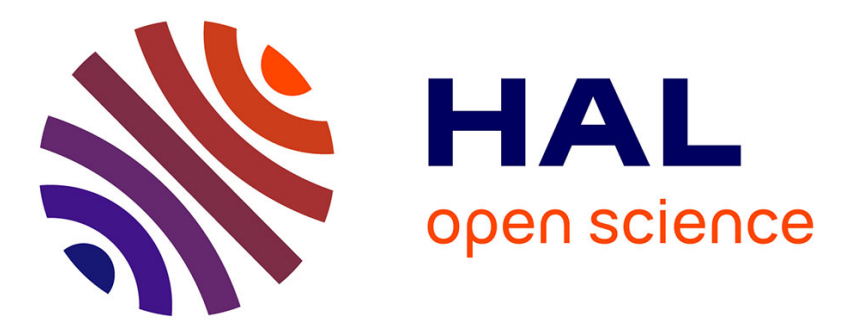

\title{
Stable isotopes reveal the common winter moult of central rectrices in a long-distance migrant songbird
}

Frédéric Jiguet, Kevin J Kardynal, Markus Piha, Tuomas Seimola, José Luis

Copete, Michel Alexandre Czajkowski, Valery Dombrovski, Ron Efrat, Simonas Minkevicius, Marko Raković, et al.

\section{To cite this version:}

Frédéric Jiguet, Kevin J Kardynal, Markus Piha, Tuomas Seimola, José Luis Copete, et al.. Stable isotopes reveal the common winter moult of central rectrices in a long-distance migrant songbird. Wilson journal of ornithology, 2019, 160 (4), pp.1077-1085. 10.1007/s10336-019-01671-w * hal-02983591

\section{HAL Id: hal-02983591 \\ https://hal.science/hal-02983591}

Submitted on 30 Oct 2020

HAL is a multi-disciplinary open access archive for the deposit and dissemination of scientific research documents, whether they are published or not. The documents may come from teaching and research institutions in France or abroad, or from public or private research centers.
L'archive ouverte pluridisciplinaire HAL, est destinée au dépôt et à la diffusion de documents scientifiques de niveau recherche, publiés ou non, émanant des établissements d'enseignement et de recherche français ou étrangers, des laboratoires publics ou privés. 
Frédéric Jiguet ${ }^{1 *}$, Kevin J. Kardynal ${ }^{2}$, Markus Piha ${ }^{3}$, Tuomas Seimola ${ }^{4}$, José Luis Copete ${ }^{5}$, Michel

Alexandre Czajkowski ${ }^{6}$, Valery Dombrovski ${ }^{7}$, Ron frat $^{8}$, Simonas Minkevicius ${ }^{9}$, Marko Raković ${ }^{10}$, Michał

Skierczyǹski ${ }^{11}$, Keith $\mathrm{A}$. Hobson ${ }^{2,12}$

7

*corresponding author: frederic.jiguet@mnhn.fr, tel +33(0)140793423

9

${ }^{1}$ CESCO, UMR7204 MNHN-CNRS-Sorbonne Université, CP135, 43 Rue Buffon, 75005 Paris, France.

${ }^{2}$ Environment and Climate Change Canada, 11 Innovation Boulevard, Saskatoon, Saskatchewan, S7N 3H5, Canada.

${ }^{3}$ Finnish Museum of Natural History LUOMUS, University of Helsinki, P.O.Box 17 (Pohjoinen Rautatiekatu 13), Fl-00014 University of Helsinki, Finland. markus.piha@helsinki.fi

${ }^{4}$ Natural Resources Institute Finland (Luke), Natural Resources, Latokartanonkaari 9, 00790 Helsinki, Finland

${ }^{5}$ Handbook of the Birds of the World Alive, Lynx Edicions, Montseny 8, 08193 Bellaterra, Spain. jlcopete@hbw.com

${ }^{6}$ OMPO, 59 rue Ampère, 75017 Paris, France. vanneau@ompo.org

${ }^{7}$ Institute of Zoology, National Academy of Sciences, Academichnaya 27, 220072, Minsk, Belarus. valdombr@rambler.ru

${ }^{8}$ Mitrani Department of Desert Ecology, The Jacob Blaustein Institute for Desert Research, BenGurion University of the Negev, Midreshet Ben-Gurion, Israel

${ }_{9}^{9}$ Pajautos st. 11-40, LT 06203, Vilnius, Lithuania.simonas.minkevicius@yahoo.com

\footnotetext{
${ }^{10}$ Natural History Museum of Belgrade, Njegoševa 51, Serbia. markorakovic@gmail.com
} 
${ }^{11}$ Department of Behavioural Ecology, Adam Mickiewicz University, Poznan, Poland, Dziczenie.pl,

27 Gruszki, Poland. skierczynski.michal@gmail.com

$28{ }^{12}$ Dept. Biology and Environment and Climate Change Canada, University of Western Ontario, Room

292025 BGS Building, 1151 Richmond St. N., London, Ontario, N6A 5B7, Canada. 
Abstract

By analysing deuterium concentration in scapulars and in rectrices $\left(\delta^{2} \mathrm{H}_{\mathrm{f}}\right)$ of breeding and spring migrating Ortolan Buntings (Emberiza hortulana), we found a high correlation attesting that spring body and central rectrices have grown in similar isotopic environments. Furthermore, we failed to find a correlation between $\delta^{2} \mathrm{H}_{\mathrm{f}}$ of rectrices and amount-weighted growing season precipitation $\delta^{2} \mathrm{H}_{p}$ of sites where we captured the birds. Winter grown body coverts and rectrices displayed similar probabilistic assignments to origin. Further examination of 76 tails of breeding birds captured in Finland in May-June confirmed that breeding birds wear recently moulted central rectrices. The body coverts are known to moult during the winter partial moult in that species, but the rectrices were reported to moult only once a year, during the complete post breeding moult occurring on the breeding grounds in summer. Here we reveal the common replacement of the central pair in winter too. The winter tail moult could occur beyond the central pair in some individuals, but this has still to be confirmed or refuted, by e.g. further isotopic investigations.

Keywords: Deuterium. Emberiza hortulana. Moulting strategy. Ortolan Bunting. Tail feather. 
Bird feathers wear and fade and so lose their effectiveness for flight, thermoregulation, protection and communication (Bridge 2008). Consequently, the renewal of flight (primaries, secondaries, tertials and rectrices) and body feathers through moult is necessary to maintain their functions and ensure the future productivity and survival of the individual (Merilä \& Hemborg 2000). Songbirds typically renew flight feathers once each year and very few species renew them twice each year, in a 'biannual moult' (Underhill et al. 1992, Kiat et al. 2018). Body coverts are renewed once or twice per year, the latter strategy being especially common in species with sexually dimorphic plumages including elaborated ornamental traits during the breeding season (Beltran et al. 2018).

The annual cycle of migratory songbirds includes breeding, moult and migration, which are all time and energy consuming and typically occur at distinct times of the year. In the Western Palearctic region, all resident adult and some juvenile passerines moult immediately after breeding by renewing the entire plumage (Kiat et al. 2018). Similarly, all adult short-distance migrants replace their feathers in summer before migration, while some long-distance migrants undergo a winter moult in the tropics after the autumn migration (Kiat et al. 2018).

Emberizidae buntings include resident, short-distance and long-distance migrant species. Most of these buntings have a complete post-breeding (summer) moult, resulting in a uniform onegeneration plumage in autumn, and most of them have a partial winter moult renewing body coverts, tertials and some wing coverts, but normally no primaries and few rectrices (Demongin 2013). Hence, spring buntings should wear quite old rectrices grown during the preceding summer, either in the nest for second-calendar year birds, or during the post-breeding moult in older adults. These feathers should be 9-10 months old in May/June. There are some exceptions to this pattern, such as the Blackheaded Bunting E. melanocephala and the Red-headed Bunting E. bruniceps which have a partial summer moult and a complete winter moult, both in adults and first-years, resulting in a uniform onegeneration plumage in spring. Some eastern Palaearctic buntings have no partial pre-breeding moult, the spring colored plumage being revealed by abrasion of the winter plumage resulting from the postbreeding complete moult. In this study, we focused on the Ortolan Bunting Emberiza hortulana, a long- 
distance trans-Saharan migrant. The Ortolan Bunting has a complete post-breeding moult, so that autumn migrants display an almost complete new plumage (including primaries, rectrices and body coverts), and a pre-breeding moult reported as partial (Svensson 1992), so that breeding birds should wear winter-grown body coverts, but older primaries and rectrices grown during the previous summer. The secondaries can be renewed during the post-breeding moult, if they are not moulted on the wintering grounds, a pattern called a split moult (Nikolaus \& Pearson 1991). Some authors reported the optional winter replacement of a few rectrices, often restricted to the central pair, though the frequency of such a replacement is not known (Jenni \& Winkler 1994).

Deuterium concentration in feathers $\left(\delta^{2} \mathrm{H}_{f}\right)$ show a latitudinal gradient across most continents that is linked to patterns of $\delta^{2} \mathrm{H}$ in amount-weighted growing season precipitation $\left(\delta^{2} \mathrm{H}_{p}\right.$; Bowen et al. 2005, Hobson et al. 2012). By converting an amount-weighted growing season $\delta^{2} H_{p}$ surface to a $\delta^{2} H_{f}$ isoscape using a calibration equation for songbirds (Prochazka et al. 2013), several studies have delineated the probable moulting areas of sampled populations (Royle \& Rubenstein 2004, Hobson \& Wassenaar 2018). Such probabilistic assignments have been published previously for Ortolan Buntings (Jiguet et al. 2019).

By analyzing $\delta^{2} \mathrm{H}_{f}$ values in Ortolan Buntings, we sought to establish a species-specific calibration equation between $\delta^{2} H_{f}$ and $\delta^{2} H_{p}$ and to possibly contrast this relationship with that established for other European passerines (e.g. Prochazka et al. 2013). As in Europe $\delta^{2} H_{p}$ has a neat latitudinal structure (Bowen et al. 2005), we expected $\delta^{2} H_{f}$ measures for rectrices to correlate either with the latitude, or with growing season $\delta^{2} H_{p}$, or with mean annual $\delta^{2} H_{p}$ of the site where we collected the feathers. If not, a first hypothesis could be that rectrices have effectively grown on breeding grounds the previous year, but natal and breeding dispersal are so high that there is no correlation in $\delta^{2} \mathrm{H}_{\mathrm{p}}$ of sites occupied in two consecutive years. This is however highly improbable given the high interannual site fidelity of territorial males (Dale 2001, 2016) and the genetic isolation of northern European populations (Moussy et al. 2017). If the correlations are confirmed, the alternative hypothesis is that rectrices have grown on the wintering grounds, as did the body coverts (Jiguet et al. 2019). To confirm 
this, we further compared $\delta^{2} \mathrm{H}_{\mathrm{f}}$ values of tail and body feathers for a set of breeding males and of spring migrating adults of both sexes. We also compared the probabilistic assignments to origin of body coverts and tail feathers for individuals captured along the eastern flyway during the spring migration. We finally examined photos of a large set of breeding birds from Finland to confirm this pattern and discuss the possible extent of the winter tail moult.

\section{Methods}

Feather sampling

We obtained one rectrix and several scapular coverts from males $(n=74)$ breeding at various sites distributed across eight countries in Europe. Sampling sites are depicted in Fig. 1: Catalonia-Spain $(n=6)$, Serbia (6), southern France (5), western France (4), Alpine France (2), eastern Poland (1), western Poland (3), Lithuania (6), Belarus (7), Belgorod-Russia (6), Volgograd-Russia (6), VladimirRussia (6), southwestern Finland (8), eastern Finland (3) and northern Finland (5). From each bird, we sampled one of the two central rectrices (R1), except in Spain where we collected one outermost rectrix (R6). We also collected one central rectrix and 4-6 scapulars on migrant individuals (males and females) captured and ringed in Kuwait $(n=45)$ and Israel $(n=10)$ in spring (April 2015).

\section{Hydrogen isotopic measurements}

Feathers were cleaned in 2:1 chloroform:methanol solvent rinse and prepared for $\delta^{2} \mathrm{H}$ analysis at the Stable Isotope Laboratory of Environment Canada, Saskatoon, Canada. The $\delta^{2} \mathrm{H}$ value of the nonexchangeable hydrogen of feathers was determined using the comparative equilibration method using CBS and KHS reference materials (Wassenaar and Hobson 2003). We performed hydrogen isotopic measurements on $\mathrm{H}_{2}$ gas derived from high-temperature $\left(1350^{\circ} \mathrm{C}\right.$ ) flash pyrolysis (Eurovector 3000 ; Milan, Italy) of $350 \pm 10 \mu \mathrm{g}$ feather subsamples and keratin standards loaded into silver capsules. We analyzed the resultant separated $\mathrm{H}_{2}$ on an interfaced Isoprime (Crewe, UK) continuous-flow isotoperatio mass spectrometer. Measurements of the two keratin laboratory reference materials corrected 
124 for linear instrumental drift were both accurate and precise with typical within-run mean $\delta^{2} \mathrm{H} \pm \mathrm{SD}$

125 values of $-197 \pm 0.79 \%$ o $(n=5)$ for CBS and $-54.1 \pm 0.33 \%$ o $(n=5)$ for KHS. We reported all results for non-exchangeable $\mathrm{H}$ expressed in the typical delta notation, in units of per mil (\%), and normalized on the Vienna Standard Mean Ocean Water-Standard Light Antarctic Precipitation (VSMOW-SLAP) standard scale.

\section{Statistical analyses}

131

We performed linear models to estimate the Pearson's correlation coefficient between (i) $\delta^{2} H_{f}$ values in rectrices and the latitude, the growing season $\delta^{2} H_{p}$ and the mean annual $\delta^{2} H_{p}$ of the sites where the feathers were sampled (for breeding birds, $n=74$ ), and (ii) the $\delta^{2} H_{f}$ values of body coverts, first separately for individuals sampled on breeding sites and for individuals sampled in spring along the migration flyway in Kuwait and Israel; second merging both datasets ( $n=129)$. Very few single samples were obvious outliers within the dataset, probably because a sampled feather had a particular history, likely it had grown at an unusual site following accidental loss and replacement. Data points with large residuals (outliers) and/or high leverage may distort the outcome and accuracy of a regression. In such conditions, Cook's distance (CD) measures the effect of deleting a given observation, while points with a large CD merit closer examination in an analysis (Cook 1977). To check for the effect of such samples on the correlations studied here, we estimated the $C D$ for each sample, and reran the linear models after excluding samples with CD values above a cut off value. Since Cook's distance is in the metric of an $F$ distribution with $p$ and $(n-p)$ degrees of freedom, the median point, i.e., $F 0.5(p, n-p)$ can be used as a cut-off. Since this value is close to 1 for large $n$, a simple operational guideline of DC $>1$ can be retained (Bollen \& Jackman 1990). Van der Meer et al. (2010) proposed $4 / n$ (where $n$ is the sample size) as the cut-off value to identify the most influential data points, to be examined as being potential outliers. We therefore retained these two cut-off values ( 1 and $4 / n)$ to test for the robustness of the detected correlation to the exclusion of the most influential data points hence potential outliers. 
151 We used a spatially-explicit likelihood assignment method to delineate probable African origins for the 152 feathers sampled on spring migrants captured in Kuwait and Israel $(n=55)$. We converted an amountweighted growing season precipitation surface (Bowen et al. 2005) to a feather isoscape using a calibration equation developed for Eurasian reed warblers (Acrocephalus scirpaceus; $\delta 2 \mathrm{Hf}=-10.29+$ 1.28* $\delta 2 \mathrm{Hp}$ ) (Procházka et al. 2013). The residual standard deviation ( $\mathrm{SD}=10.36 \%$ ) from the linear regression model used to calibrate the precipitation surface for Eurasian reed warbler feathers was included in the assignments as an estimate of error. We performed assignments to origin to the known fill range of the species, including the breeding and the wintering ranges, then to only the winter range of the populations using the eastern flyway (Jiguet et al. 2018). We obtained the digital distribution map of ortolan buntings from BirdLife International and NatureServe (2018). We used an odds ratio of 2:1 to assign each feather sample to potential origin where cells in the isoscape in the upper $67 \%$ of probabilities were considered as likely

(1) origins and all others were considered unlikely (0). Assignments resulted in a spatially explicit binary surface for individual birds, which we subsequently summed across assignments for all individuals within a group to represent potential origins for that group. For each pixel in the assignment raster, the presented value is the probability obtained for a pixel divided by the maximum probability obtained for a pixel, so range from 0 to 1 . We finally estimated the correlation coefficient between proportions obtained for the body coverts and for the rectrices across all pixels of the East African winter range, forcing the intercept to equal zero.

Photo examination of tails

We visually assessed a large set of photos of tails of breeding Ortolan Buntings from Finland, to detect possible moult contrasts in rectrices. We had photos for 71 breeding individuals (mostly of males but 173 including also females, with five individuals photographed in two years, so 76 tails*year for 71 174 individuals) taken at various sites in Finland in May or June from 2011 to 2018. We recorded the state 175 of the central pair of rectrices, as being fresh or relatively fresh, or abraded to highly abraded. We also 
reported the frequency of heavily worn and abraded tails, and of apparently fresh tails with unobvious moult contrasts - these are the two extreme states along a gradient of tail wear and abrasion. In the results and discussion, R1 designates the central rectrix, R6 the outermost, either on the right or left side of the tail (see Fig. 4 for examples).

\section{Results}

The $\delta^{2} \mathrm{H}_{f}$ values measured in rectrices of breeding ortolan buntings $(n=74)$ did not correlate neither with the latitude ( $r=0.095, \mathrm{P}>0.2$; Fig. $\mathrm{S} 1)$, nor with growing season $\delta^{2} \mathrm{H}_{\mathrm{p}}(\mathrm{r}=0.030, \mathrm{P}>0.5$; Fig. 1$)$ or mean annual $\delta^{2} H_{p}\left(r=0.044, P>0.5\right.$; Fig. S1) where we collected the feathers. The $\delta^{2} H_{f}$ values measured in body coverts of the same birds did not correlate either with growing season $\delta^{2} H_{p}(r=0.186, P>0.1$; Fig. S1). However, rectrices and body coverts taken on the same males captured on their breeding territories across Europe had similar $\delta^{2} H_{f}$ values and significant correlation ( $n=74, r=0.67, P<0.001$; Fig. 2). In this dataset, no sample had a $C D$ value $>1$. If excluding the two samples with $C D$ values $>4 / n$, the correlation coefficient increased to $0.83(n=72)$. Note that there are some substantial variations in $\delta^{2} H_{f}$ values within the sample of breeding birds, as the wintering grounds are widespread across the Sahel in western and eastern Africa, including substantial variations in $\delta^{2} \mathrm{H}_{\mathrm{p}}$ (see Gutiérrez-Espósito et al. 2015). Variations of $\delta^{2} \mathrm{H}_{\mathrm{f}}$ values are more restricted for the spring samples obtained in Kuwait and Israel as it most likely concerns migrants coming back from the wintering grounds in eastern Africa only.

For the buntings captured in Kuwait and Israel during the spring migration, we found a similar positive correlation between body coverts and rectrices $(r=0.67, n=55, P<0.001$; Fig. 3). Only one sample had a CD value $>1$, and after excluding it, Pearson's correlation coefficient was $0.77(n=54)$. When the 5 influential points with CD values over $4 / n$ were excluded, the correlation coefficient was $0.80(n=51)$. The values of probabilistic assignments to origin obtained across the East African winter range were also significantly correlated between body coverts and central rectrices across all pixels $(y=0.998 x, n=333$ pixels; $r=0.62, P<0.001)$. The probability assignment maps obtained for the body 
coverts and the rectrices for the whole species range and restricted to the East African wintering range are illustrated in Fig. 4.

Merging the two previous datasets (breeding and migrating birds), the correlation coefficient was $r=0.76(n=129, P<0.001)$, and when the 3 samples with a $C D$ value $>1$ were excluded, $r=0.86$ ( $n=126)$. Running a general linear model predicting feather $\delta^{2} \mathrm{H}$ in body coverts by $\delta^{2} \mathrm{H}$ in rectrices for this subset of 126 samples, we obtained the following parameter estimates and associated confidence intervals (2.5\%-97.5\%): intercept $-7.31 \pm 1.98 \%$ o $(-11.18--3.43 \%$ ), slope $0.95 \pm 0.06(0.83-1.07)$. The intercept was significantly different from zero but the slope was not different from 1 , signaling equal values of $\delta^{2} \mathrm{H}$ in body and rectrices once adjusted to the intercept. For the intercept, the upper limit of the confidence interval $(-3.43 \%$ ) is close to previously reported measurement errors in keratin control reference (SD of $\pm 3.3 \%$ in Hobson et al. 2012; measurement error of 3\% in Gutiérez-Espósito et al. 2015).

Among the 76 tails of breeding ortolan buntings which we examined from photos, 7 displayed obvious moult contrasts due to ongoing active moult, corresponding to: actively growing R1 and/or R2 on one side of the tail $(n=5)$; actively growing R1 to R6 on one side (one half of the tail made of growing feathers all similar length, $n=1)$; recently renewed $R 5$ on the right side $(n=1)$. These patterns most probably correspond to the replacement of accidentally lost rectrices, given their asymmetry and timing. Four tails displayed one $(n=1)$ or two old and highly abraded central rectrices, representing $5 \%$ of the sample. All other tails have relatively fresh central rectrices, and 15 of them seem to be composed of relatively unworn other feathers on whole tail (R2-6), representing $20 \%$ of the sample, and including both second calendar year and older individuals.

\section{Discussion}

Stable isotopes may provide interesting results when studying moult strategies, but are still used infrequently (but see Neto et al. 2006, Inger \& Bearhop 2008). Here, while analysing measures of deuterium concentrations in the feathers of Ortolan Buntings, we found that all individuals moulted 
their central rectrices in winter. Indeed, the lack of relationship between mean growing season $\delta^{2} \mathrm{H}$ values in precipitation and $\delta^{2} \mathrm{H}$ values in rectrices collected in spring suggests that these feathers have not grown on their breeding grounds the year before. Ortolan Buntings replace the body coverts twice each year: during the post-breeding moult on the breeding grounds and during the pre-breeding moult on the wintering grounds. Indeed, the analysis of $\delta^{2} \mathrm{H}$ values in scapulars allowed the determination of the wintering grounds of European breeding Ortolan Buntings (Jiguet et al. 2019). For the males studied here, we compared the $\delta^{2} \mathrm{H}$ values in tail and body feathers collected simultaneously in spring on breeding grounds, and discovered that these two values were highly correlated (Fig. 2). This holds also true for a set of 55 individuals of unknown sex sampled in the Middle East in April during their spring migration (Fig. 3) between their wintering grounds on the Ethiopian highlands and their breeding grounds in Eastern Europe (Jiguet et al. 2019). For these Middle Eastern spring migrants, we also found similar probabilistic assignments to origins for the two types of feathers. Merging the two datasets, we obtained a proportion coefficient not different from 1 , meaning that the $\delta^{2} \mathrm{H}$ values in these two types of feathers are similar; hence the feathers should have grown in isotopically similar environments, evidently on the African wintering grounds. This can be considered as the general rule, as we found only 3 potential outliers within the sample of 129 spring individuals originating from varied European populations using either the western (from northern, central and western Europe to western Africa) or the eastern flyway (from eastern Europe and southern Russia to eastern Africa) (Jiguet et al. 2019). The generality of this rule is further confirmed by the high proportion (95\%) of Finnish breeding birds having recently renewed central rectrices in May-June.

The Ortolan Bunting was considered noteworthy for replacing all or part of secondaries on wintering grounds (Nikolaus \& Pearson 1991, Hedenström et al 1992), a split moult pattern shared only by a few Palearctic songbirds (Kiat et al. 2018), such as the Barred Warbler Sylvia nisoria (Lindström et al. 1992). According to our results, the Ortolan Bunting would also be noteworthy for commonly replacing central rectrices during the pre-breeding moult on the wintering grounds, 
regardless of their age or origin. As these rectrices are also replaced during the post-breeding moult, the Ortolan Bunting displays a biannual moult of central rectrices.

The scheduling of moult is essentially the result of trade-offs between having high feather quality during breeding, migration or the non-breeding period (Holmgren \& Hedenström 1995). A high impact of feather quality on survival rate in combination with relatively low costs of moult can result in an advantage to develop a biannual moult (Holmgren \& Hedenström 1995). Winter food abundance can further limit the extent and timing of the pre-breeding moult (Barta et al. 2006, 2008, Danner et al. 2015). The Ortolan Bunting is one of the few trans-Saharan migrant buntings in Europe, which forages on ground in open, hot and sunny regions in winter, at locations where daylight temperatures regularly reach $40-45^{\circ} \mathrm{C}$ (unpublished data from light loggers). Rectrix wear and bleaching probably occurs extensively there during winter, especially for the central pair which is exposed continuously to sun light. The biannual moult of the central rectrices is probably necessary to ensure that other rectrices are protected from wear and bleaching during the winter, so that the spring migration journey are performed with a totally functional tail rudder. Other long-distance migrant ground-foraging buntings (Cretzschmar's E. caesia and Cinereous Buntings E. cineracea) winter in hot and dry parts of Africa, e.g. along southern Red coasts, and probably also moult central rectrices in winter. In Europe, more sedentary buntings do not moult central rectrices in winter, even during the first-year, such as Cirl E. cirlus and Rock Buntings E. cia (Demongin 2013).

Cramp \& Perrins (1994) reported that the first pre-breeding moult for $2^{\text {nd }}$ calendar year Ortolan Buntings can include a variable number of greater coverts and rectrices. However, the isotopic analyses presented here indicated that all Ortolan Buntings, whatever their age, renew central rectrices in winter. Within the few exceptions (e.g. old worn unmoulted central rectrices) detected visually among tails of Finnish breeding birds, all could be aged as $2^{\text {nd }}$ calendar years owing to the pointed pattern of outer primary coverts, of retained first generation rectrices and heavily abraded primaries. As most samples studied here concern central rectrices, we provide isotopic evidence that at least these central rectrices have grown on the African moulting grounds before the spring migration. A partial winter 
renewal of rectrices is indeed a common strategy in songbirds wintering in Sub-Saharan and tropical Africa (Kiat et al. 2018). The extent of this pre-breeding tail moult in Ortolan Bunting might however probably be larger, an hypothesis supported by several observations. First, all six birds from Spain, for which we sampled outermost and not central rectrices, fit the isotopic pattern of all other individuals (see crossed dots in Fig. 2). However, this should be confronted to $\delta^{2} H_{f}$ values of feathers grown in Spain, which could be similar. Second, part of the Finnish breeding birds had a complete set of relatively fresh rectrices ( $20 \%$ of the sample), which could be well preserved ca. 9 month old feathers, or possibly winter moulted feathers. To further test if the winter tail moult could extend beyond the central rectrices, further isotopic analyses are needed. Kiat et al. (2018) also report the existence of two moult periods in some species while in sub-Saharan Africa: one in autumn in northern Sahel, and in late winter on wintering grounds. It is possible that in Ortolan Bunting, some individuals moult the rectrices in the early period, and other just prior to spring return migration. This could cause some variation in feather abrasion and wear as observed in spring (see Fig. 4), though other environmental or internal factors could lead to such variable abrasion.

Jenni \& Winkler (1994) are the only authors who reported details on a pre-breeding moult of rectrices for 13 Ortolan Buntings. Eight of them had all same-generation feathers, suspected to be old unmoulted $(n=7)$ or recently moulted $(n=1)$ feathers. Furthermore, they reported that four moulted the central pair and one moulted the two central and the two outermost pairs of rectrices. Within this sample, less than half of the birds are reported to have renewed the central rectrices in winter. This pattern was in line with the previously published elements on an optional replacement of central rectrices in winter (Cramp \& Perrins 1994), which optionality is challenged here by isotopic analyses. This illustrates the potential contribution of isotopic analyses to the understanding of moult timing in migrant birds that we do not catch frequently during a large part of the year, when they winter in remote African habitats (Neto et al. 2006). This also illustrates the difficulty to detect this common moult by visual inspection only, and the interest to rely on isotopic analyses. 
We are grateful to all colleagues who helped in the field work, monitoring and capturing buntings. We

thank two anonymous reviewers who provided important insights to clarify the moult patterns of

buntings. This research was funded by Conseil Général des Landes, Région Aquitaine, Région Nouvelle

Aquitaine, Fédération Départementale des Chasseurs des Landes (FDC40), Association

Départementale des Chasses Traditionnelles à la Matole (ADCTM), French Ministry in charge of the

Environment. Environment and Climate Change Canada supported the stable isotope analyses through

\section{References}

Barta Z, Houston Al, McNamara JM, Welham RK, Hedenström A, Weber TP, Feró O (2006) Annual routines of non-migratory birds: optimal moult strategies. Oikos 112, 580-593.

Barta Z, McNamara JM, Houston Al, Weber TP, Hedenström A, Feró O (2008) Optimal moult

Beltran RS, Burns JM, Breed GA (2018) Convergence of biannual moulting strategies across birds and mammals. Proc R Soc Lond B 285: 20180318. doi: 10.1098/rspb.2018.0318

BirdLife International, NatureServe (2018) Version 1.0. BirdLife International, Cambridge, UK and NatureServe, Arlington, USA.

Bollen KA, Jackman RW (1990) Regression Diagnostics: An Expository Treatment of Outliers and Influential Cases. In: Fox J, Long JS (eds) Modern Methods of Data Analysis. Newbury Park, CA: Sage, pp. 257-291

Bowen GJ, Wassenaar LI, Hobson KA (2005) Global application of stable hydrogen and oxygen isotopes to wildlife forensics. Oecologia 143: 337-348

Bridge ES (2008) How does imping affect wing performance? J. Wildlife Rehab. 29: 4-9. 
Cramp S, Perrins CM (1994) Ortolan Bunting Emberiza hortulana. In Handbook of the birds of Europe, the Middle East end North Africa - The birds of the Western Paleartic - Volume IX - Buntings and New world warblers. Oxford University press, Oxford, UK and New-York, USA, pp. 209 - 223.

Dale S (2001) Female-biased dispersal, low female recruitment, unpaired males, and the extinction of small and isolated bird populations. Oikos 92, 344-356

Dale S (2016) Cost of reproduction: a comparison of survival rates of breeding and non-breeding male ortolan buntings. J Avian Biol 47, 583-588

Danner RM, Greenberg RS, Danner JE, Walters JR (2015) Winter food limits timing of pre-alternate moult in a short-distance migratory bird. Funct Ecol 29: 259-267

Demongin L (2013) Guide d'identification des oiseaux en main. Baume-les-Dames, France.

Gutiérrez-Expósito C, Ramírez F, Afán I, Forero MG, Hobson KA (2015) Toward a Deuterium Feather Isoscape for Sub-Saharan Africa: Progress, Challenges and the Path Ahead. PLoS ONE 10(9): e0135938. https://doi.org/10.1371/journal.pone.0135938

Hedenström A, Bensch S, Hasselquist D, Lindström Å, Åkesson S, Pearson DJ (1992) Split moult: Stress or strategy? Ringing Migr 13: 179-180

Hobson KA, Wassenaar LI (2018) Tracking Animal Migration using Stable Isotopes. Second edition, Academic PressLondon, UK.

Hobson KA, Van Wilgenburg SL, Wassenaar LI, Larson K (2012) Linking Hydrogen $\left(\delta^{2} H\right)$ Isotopes in Feathers and Precipitation: Sources of Variance and Consequences for Assignment to Isoscapes. PLoS One 7(4): e35137

Holmgren N, Hedenström A (1995) The scheduling of molt in migratory birds. J Evol Ecol 9: 354-368 Inger R, Bearhop S (2008) Applications of stable isotope analyses to avian ecology. Ibis 150, 447-461 Jenni L, Winkler R (1994) Moult and ageing of European passerines. A\&C Black, London, UK. ISBN 0-

$$
12-384150-X
$$

Jiguet F, Robert A, Lorrillière R, Hobson KA, Kardynal KJ, Arlettaz R, Bairlein F, Belik V, Bernardy P, Copete JL, Czajkowski MA, Dale S, Dombrovski V, Ducros D, Efrat R, Elts J, Ferrand Y, Marja R, 
Minkevicius S, Olsson P, Pérez M, Piha M, Raković M, Schmaljohann H, Seimola T, Selstam G, Siblet J-P, Skierczyǹski M, Sokolov A, Sondell J, Moussy C (2019) Unravelling migration connectivity reveals unsustainable hunting of the declining ortolan bunting. Science Advances Jiguet F, Pons J-M, Copete JL, Czajkowski MA, Dale S, Dombrovski V, Elts J, Grzegorczyk E, Lorrillière R, Marja R, Minkevicius S, Olsson P, Pérez M, Piacentini J, Piha M, Raković M, Seimola T, Selstam G, Skierczyǹski M, Sondell J, Thibault J-C, Moussy C (submitted) Diurnal stopover strategy of migrating songbirds to cross desert barriers.

Kiat Y, Izhaki I, Sapir N (2018) The effects of long-distance migration on the evolution of moult strategies in Western-Palearctic passerines. Biol Rev Camb Philos Soc, doi:10.1111/brv.12474.

Lindström Å, Pearson DJ, Hasselquist D, Hedenström A, Bensch S, Akesson S (1993) The moult of Barred Warblers Sylvia nisoria in Kenya-Evidence for a split wing-moult pattern initiated during the birds' first winter. Ibis 135: 403-409

Marquiss M, Newton I, Hobson KA, Kolbeinsson Y (2012) Origins of irruptive migrations by Common Crossbills Loxia curvirostra into northwestern Europe revealed by stable isotope analysis. Ibis 154: $400-409$

Merilä J, Hemborg C (2000) Fitness and feather wear in the collared flycatcher Ficedula albicollis. J. Avian Biol. 31: 504-510.

Moussy C, Arlettaz R, Copete JL, Dale S, Dombrovski V, Elts J, Lorrillière R, Marja R, Pasquet E, Piha M, Rakovic M, Seimola T, Selstam G, Jiguet F (2018) The genetic structure of the European breeding populations of a declining farmland bird, the ortolan bunting (Emberiza hortulana), reveals conservation priorities. Conserv Genet 19: 909-922

Neto JM, Newton J, Gosler AG, Perrins CM (2006) Using stable isotope analysis to determine the winter moult extent in migratory birds: the complex moult of Savi's warblers Locustella luscinioides. J Avian Biol 37, 117-124.

Newton I (2009) Moult and plumage. Ringing Migr 24: 220-226. 
Nikolaus G, Pearson D (1991) The seasonal separation of primary and secondary moult in Palaearctic passerine migrants on the Sudan coast. Ringing Migr 12: 46-47

Procházka P, Van Wilgenburg SL, Neto JM, Yosef R, Hobson KA (2013) Using stable hydrogen isotopes $\left(\delta^{2} \mathrm{H}\right)$ and ring recoveries to trace natal origins in a Eurasian passerine with a migratory divide. $\mathrm{J}$ Avian Biol 44: 541-550

Snow DW (1967) A guide to moult in British birds. British Trust for Ornithology, Thetford, UK

Royle JA, Rubenstein DR (2004) The role of species abundance in determining breeding origins of migratory birds with stable isotopes. Ecol Appl 14: 1780-1788

Svensson L (1992) Identification Guide to European Passerines. 4th Edition, British Trust for Ornithology, Stockholm

Underhill L, Prys-Jones RP, Dowsett R, Herroelen P, Johnson DN, Lawn MR, Norman SC, Pearson DJ, Tree A (1992) The biannual primary moult of Willow Warblers Phylloscopus trochilus. Europe and Africa. Ibis 134: 286-297

Van der Meer T, te Grotenhuis M, Pelzer B (2010) Influential cases in multilevel modeling. A methodological comment. Am Sociol Rev 75: 173-178 
Fig. 1. Values of $\delta^{2} \mathrm{H}$ in rectrices of 74 ortolan buntings captured in Europe (Belarus, France,

398 Lithuania, Poland, Russia, Serbia, Spain) during the breeding season (May-June) according to the

399 growing season average precipitation $\delta^{2} \mathrm{H}_{p}$ of the capture site. Insert: isoscape showing the

400 distribution of the growing season average precipitation $\delta^{2} \mathrm{H}$ across Europe (from Marquiss et al.

401 2012). Black dots are sites where feathers were sampled.

402

403

404

405

406

407

408
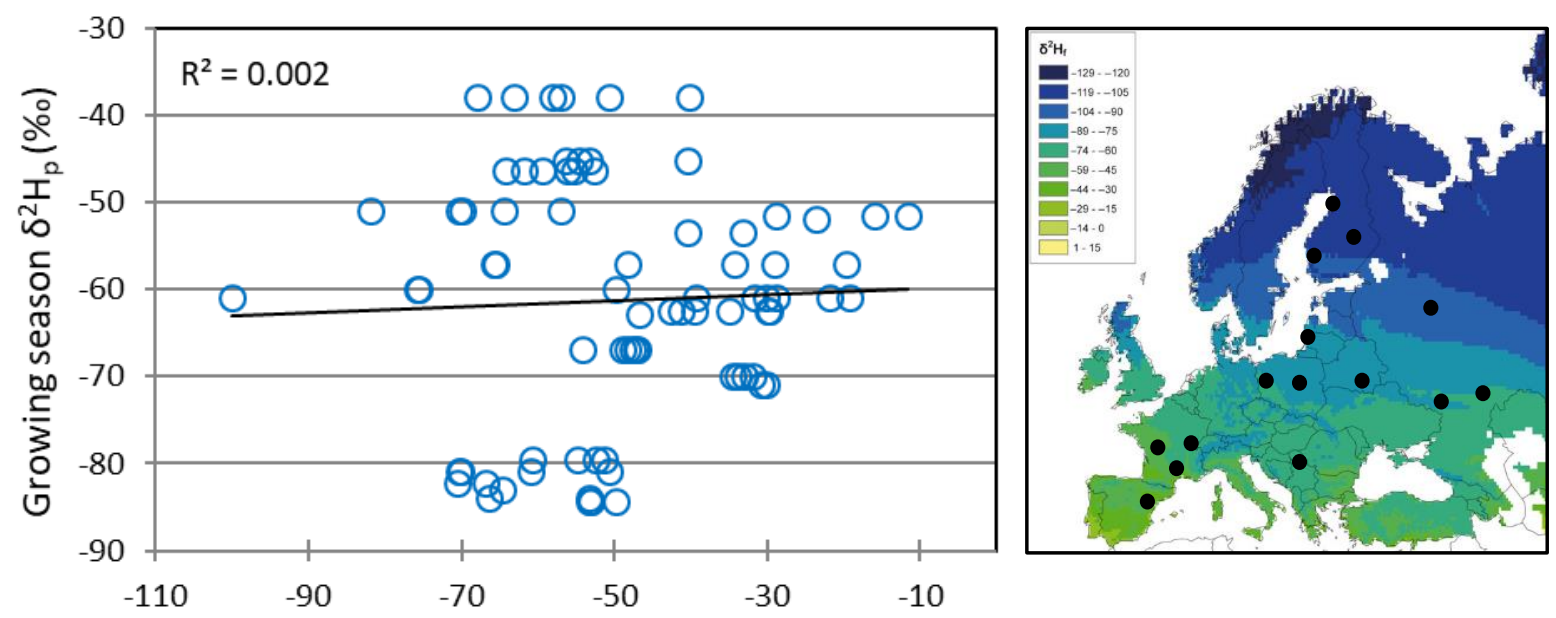

409

410

Tail feathers $\delta^{2} \mathrm{H}(\%)$ 
411 Fig. 2. Values of $\delta^{2} \mathrm{H}$ in feathers of 74 ortolan buntings captured in Europe (Belarus, Finland, France,

412 Lithuania, Poland, Russia, Serbia, Spain) during the breeding season (May-June), in rectrices (y-axis)

413 and body coverts (x-axis). Black crosses identify sampled outermost rectrices of Spanish birds. Open

414 red dots are the outliers identified by Cook's distances.

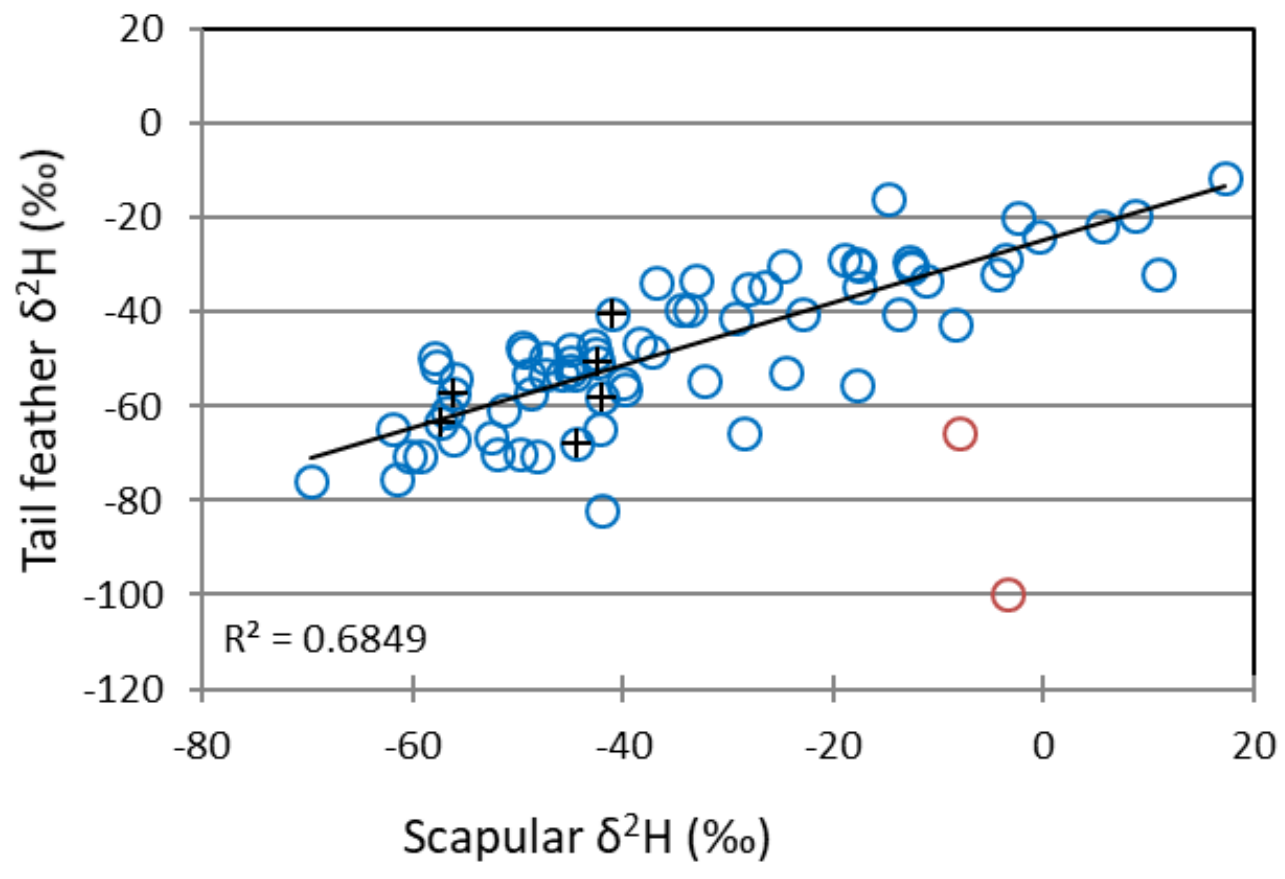


Fig. 3. Values of $\delta^{2} \mathrm{H}$ in feathers of 45 Ortolan Buntings Emberiza hortulana captured in Kuwait in April

4172015 during the spring migration, in rectrices ( $y$-axis) and body coverts ( $\mathrm{x}$-axis). Open red dots are 418 outliers identified by Cook's distances.

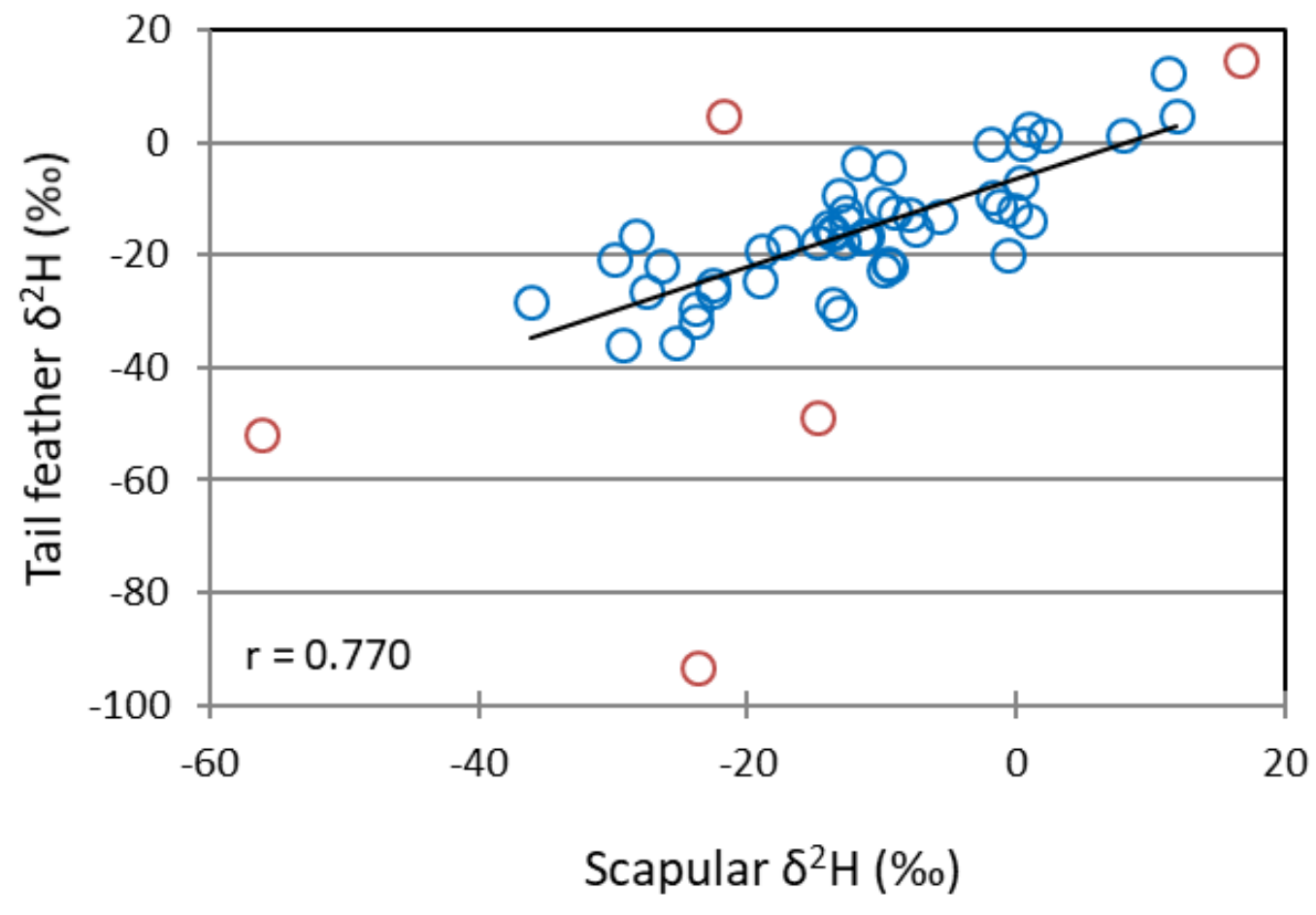


Fig. 4. Probabilistic assignment maps for the body coverts (upper row) and rectrices (lower row) as

421 obtained for the complete species range (left) or when restricting the assignment to the East African

422 winter range (right). Values are scaled to range from 0 to 1 , as raw probabilities divided by the

423 maximum value obtained for a pixel.

424
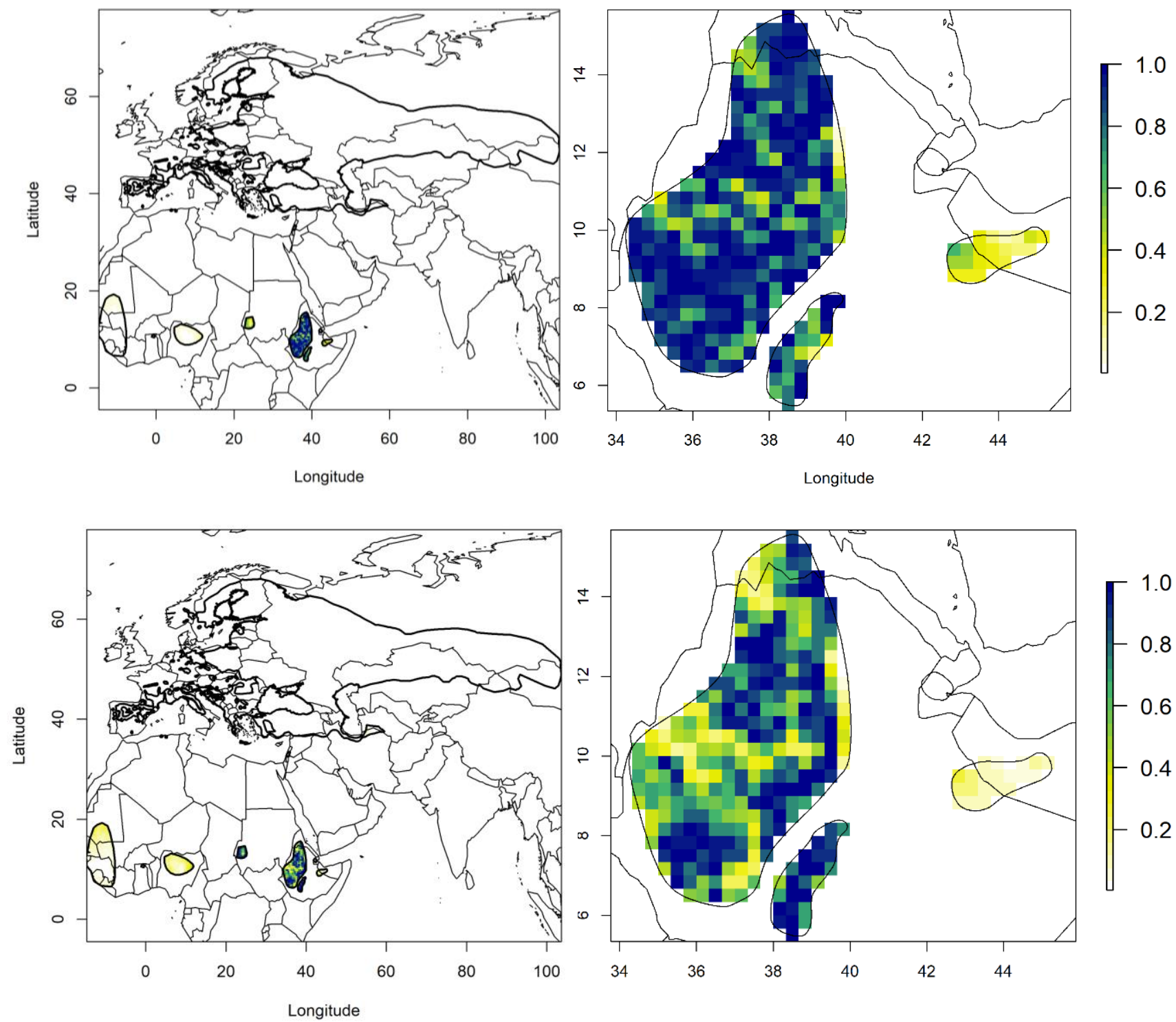
Fig. 5. Tails of adult breeding Ortolan Buntings Emberiza hortulana captured during the spring in

426

427

428

429

430

431

432

433

434

435

436

437

438

439

440

441

442

443

444

445

446

447

448

449

450

Finland. Upper left: +2cy captured 31 May 2017, with renewed central rectrices and relatively fresh

other rectrices. Upper right: 2cy captured 11 May 2017, heavily worn rectrices, either all firstgeneration unmoulted feathers, or winter moulted central rectrices with unusual heavy wear. Lower left: individual captured 5 June 2014; central rectrices browner but not heavily abraded, so have been moulted in winter; other rectrices moderately worn, but obviously less abraded than primaries; such worn primaries should sign a 2cy, but R2-6 have adult-type rounded tips, and outer primary coverts were not typically pointed; if this bird is a $2 c y$, the whole tail has been moulted in winter. Lower right: captured 22 May 2016, post-breeding rectrices but renewed left central rectrix; age unknown.
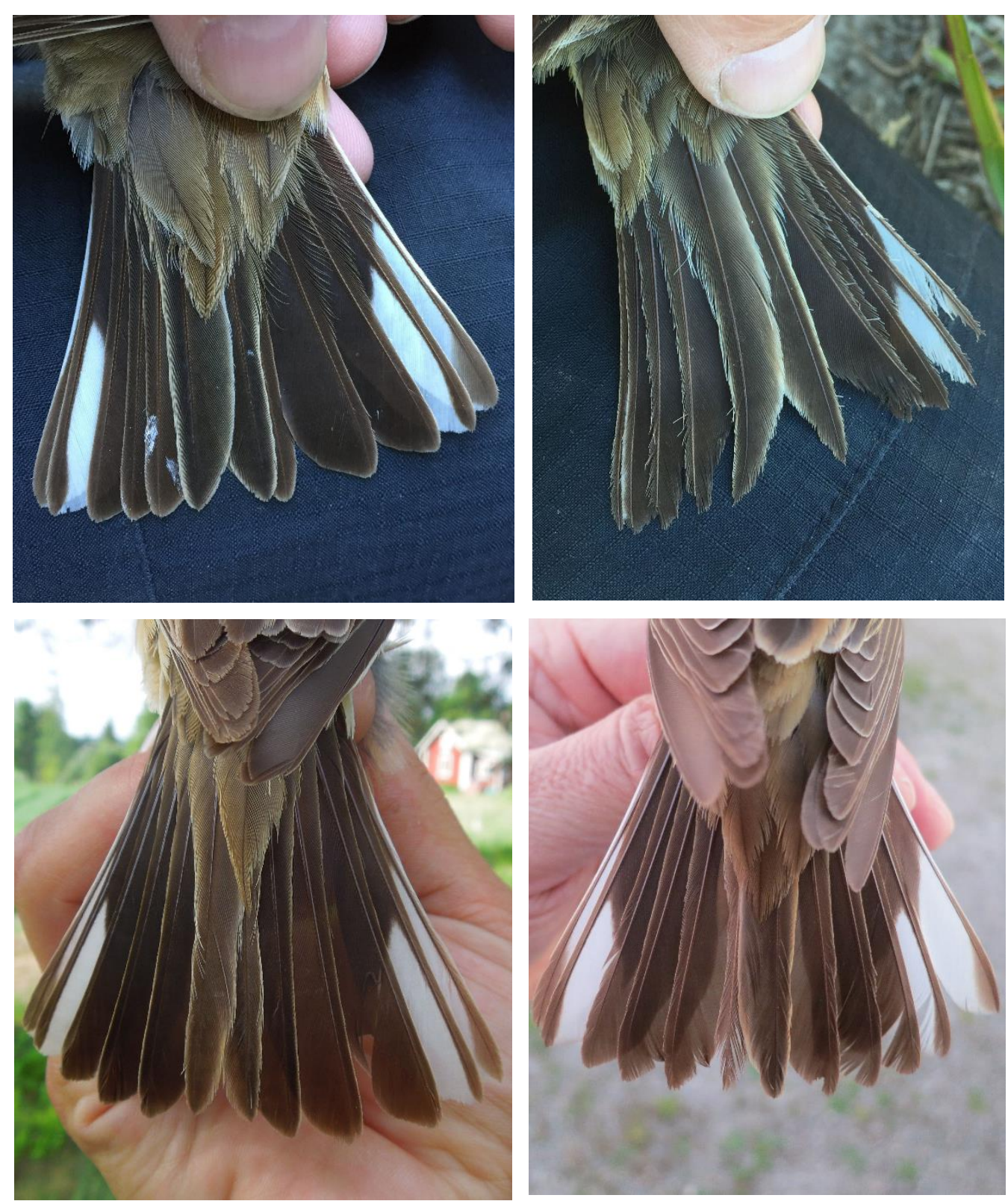
451

452

453

454 $455 \delta^{2} H_{p}$

$456 \quad(A)$

457

458

459

460

461

462

463

464

465

466

467

468

469

470

471

472

473

474

475

476

(B)

(C)

Fig. S1. Values of $\delta^{2} \mathrm{H}$ in rectrices and scapulars of 74 ortolan buntings captured in Europe (Belarus, France, Lithuania, Poland, Russia, Serbia, Spain) during the breeding season (May-June) according to the latitude of the capture site. (A): $\delta^{2} \mathrm{H}_{\mathrm{f}}$ in rectrices and latitude; (B) $\delta^{2} \mathrm{H}_{\mathrm{f}}$ in rectrices and mean annual precipitation $\delta^{2} \mathrm{H}_{p}$, and (C) $\delta^{2} \mathrm{H}_{\mathrm{f}}$ in body coverts and growing season average precipitation

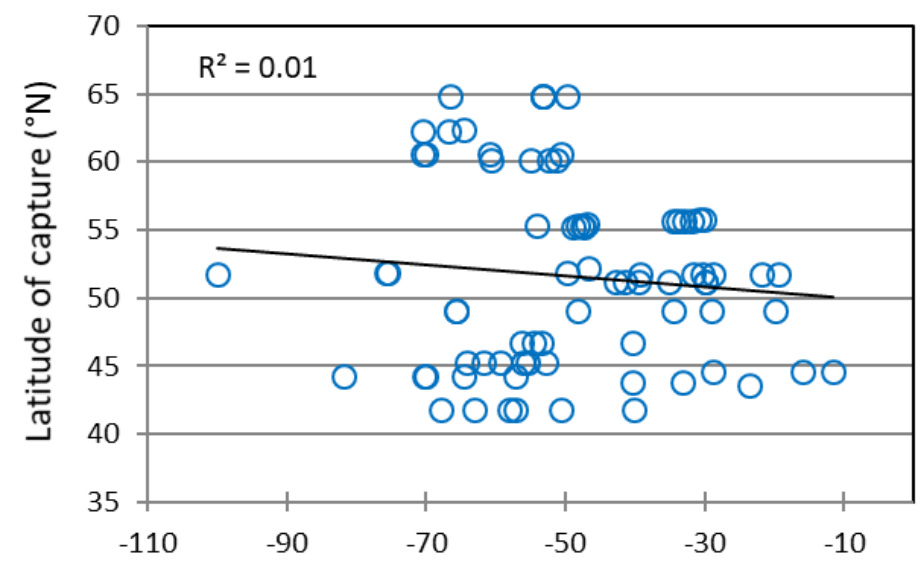

Tail feather $\delta^{2} \mathrm{H}(\%)$

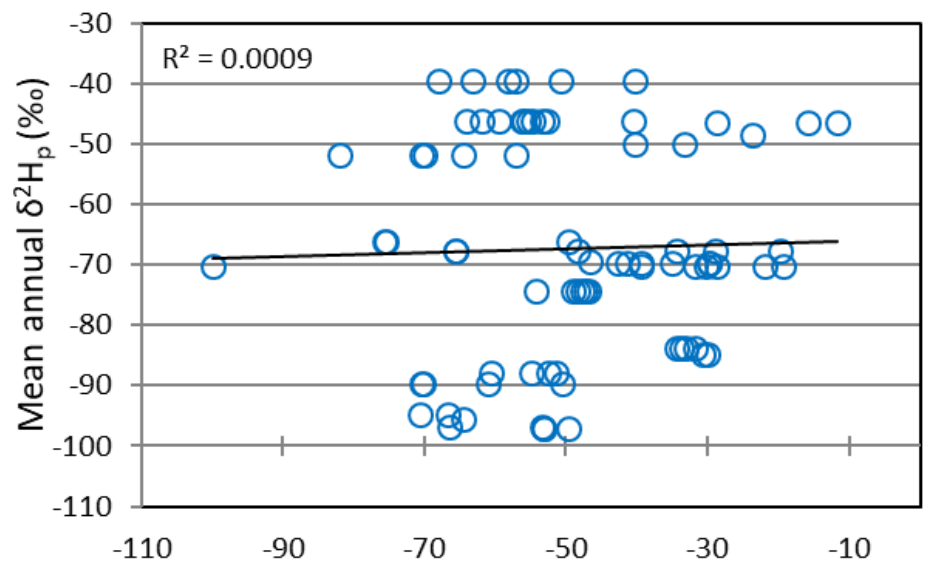

Tail feather $\delta^{2} \mathrm{H}(\%)$

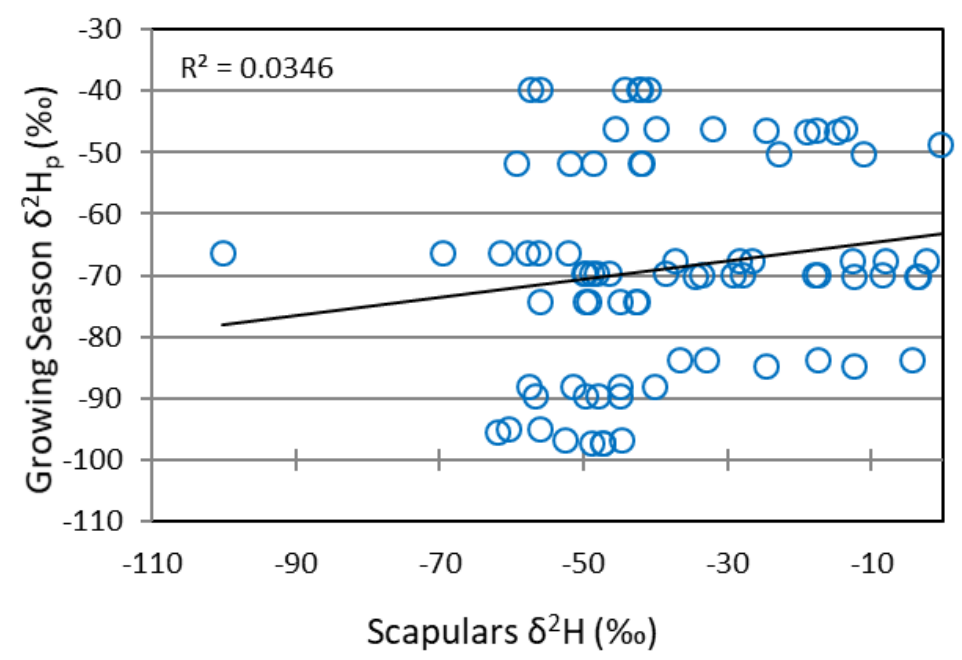

